\title{
Recovery of Tomato Plants from Ozone Injury
}

\author{
Albert Z. Tenga, Beverley A. Marie, and Douglas P. Ormrod \\ Department of Horticultural Science, University of Guelph, Guelph, \\ Ont. N1G 2W1, Canada
}

Additional index words. Lycopersicon esculentum, growth, yield, fruit quality, oxidant

Abstract. Field experiments in open-top chambers were conducted to study the recovery of tomato (Lycopersicon esculentum Mill. Cv. New Yorker) plants from ozone $\left(O_{3}\right)$ injury. Plants were pot-cultured and exposed for 7 hours per day for 4 days at a vegetative or flowering stage to charcoal-filtered air, $0.06,0.09,0.12,0.18$, or $0.24 \mu \mathrm{l}$ $\mathrm{O}_{3}$ /liter. Half of the plants were harvested 2 or 3 days after the $\mathrm{O}_{3}$ exposure; the remaining plants were held in open-top field chambers in filtered air and harvested after the appearance 'of the first red fruit. Ozone exposure at either growth stage resulted in visible foliar injury and decreased leaf area of plants harvested 2 or 3 days after exposure. In spite of extensive foliar injury after $\mathrm{O}_{3}$ exposure at the vegetative stage, there was no significant decrease in fruit yield or change in fruit quality at the final harvest. In contrast, exposure of plants to $\mathrm{O}_{3}$ at flowering progressively reduced fresh weight of fruit and, to a lesser degree, its concentration of titratable acidity.

Foliar injury ratings indicate that many tomato cultivars are sensitive to $\mathrm{O}_{3}$ (Clayberg, 1971; Ormrod, 1986; Reinert and Henderson, 1980). However, when five cultivars were exposed to $\mathrm{O}_{3}$ and ranked for foliar injury and yield response it was found that foliar injury was not a good indicator of yield loss (Oshima et al., 1977a). This result suggests either that the adverse effects of visible foliar injury on yield components are being offset by repair and recovery mechanisms or that there is enough additional noninjured leaf surface to compensate for any physiological impairment. The ability to repair and/or recover may depend on the growth stage at time of $\mathrm{O}_{3}$ exposure as well as on the concentration and duration of exposure. The effect of $\mathrm{O}_{3}$ exposures on snap bean yield has been related to the growth stage at which exposure occurred (Blum and Heck, 1980). There was partial recovery when young bean plants were exposed to $\mathrm{O}_{3}$, but not with exposure of older plants.

The objective of our research was to determine if effects of $\mathrm{O}_{3}$ on tomato growth and fruit yield and quality depend on growth stage at the time of exposure. 'New Yorker' tomato plants were exposed to $\mathrm{O}_{3}$ in opentop chambers (Heagle et al., 1973). 'New Yorker' is an early field cultivar of intermediate sensitivity to $\mathrm{O}_{3}$ (Clayberg, 1971). Its semi-determinate growth habit facilitates treatment and harvest within well-defined developmental stages. A dose-response approach was taken and the growth stages were represented by a vegetative and a flowering stage.

Received for publication 12 July 1989. Financial assistance for this research was provided by an operating grant from the Natural Sciences and Engineering Research Council of Canada. The cost of publishing this paper was defrayed in part by the payment of page charges. Under postal regulations, this paper therefore must be hereby marked advertisement solely to indicate this fact.
Experiments were conducted in 1985 and 1986 in open-top field chambers located at the Horticultural Research Station, Cambridge, Ontario. Plants were grown from seed in 22-cm-diameter (6.0 liter) green plastic pots, one plant per pot. The potting medium was a 1 sphagnum peat : 1 vermiculite : 1 perlite mixture (by volume). All plants were watered several times daily with an automatic trickle irrigation system. Nutrients were applied by hand-watering each pot three times weekly using Hoagland's complete nutrient solution (Hoagland and Arnon, 1950).

Tomato plants were exposed at two growth stages: a) when leaf 7 was longer than 10 $\mathrm{mm}$ but shorter than $20 \mathrm{~mm}$ (vegetative stage) and b) when all the flowers in the first inflorescence of each plant were in full bloom (flowering stage). Eight plants per treatment were exposed to $\mathrm{O}_{3}$ for $7 \mathrm{hr} \cdot$ day $^{-1}$ for 4 days at each growth stage. The air entering each of six open-top chambers was filtered through activated charcoal, removing $70 \$ \%$ to $75^{\prime} \%$ of the ambient $\mathrm{O}_{3}$. Ozone was generated from compressed oxygen (Corona $\mathrm{O}_{3}$ Generator, Model LG-2-L1, W.R. Grace, Columbia, Md.) added to the charcoal-filtered (CF) air in each chamber and monitored with an ultraviolet analyzer (Dasibi Model $1003 \mathrm{AH}$, Dasibi Environmental Corp., Glendale, Calif.). The $\mathrm{O}_{3}$ treatments in the chambers were $\mathrm{CF}, 0.06,0.09,0.12,0.18$, or 0.24 $\mu \mathrm{l} \cdot$ liter $^{-1}$; the concentrations fluctuated by a maximum of $\pm 0.015 \mu \mathrm{l} \cdot$ liter $^{-1}$. The experimental design was a randomized complete block with each year considered as a block. There was a factorial arrangement of $\mathrm{O}_{3}$ level $\times$ growth stage treatments. In both years, the experiments ran from 16 June to 20 Sept. Yearly temperatures were similar, with average daily chamber maxima of $27 \mathrm{C}$ in July and 21C in September.

Visible foliar injury was estimated 2 days after the end of exposure, using the HorsfallBarratt rating scale for percent of leaf surface injured (Horsfall and Barratt, 1945). The four plants at each harvest period from each $\mathrm{O}_{3}$ treatment and growth stage were individually rated. At both the vegetative and flowering stages leaf area (measured with a LI-COR Model 31000 area meter LI-COR, Lincoln, Neb.) and leaf and stem dry weights (70C for 4 days) were determined. These measurements were taken both 2 to 3 days after the last $\mathrm{O}_{3}$ exposure and following the development of the first red fruit. Data on fruit yield included number of fruits and fruit fresh and dry weights. All fruits were harvested and measured at the same time. Three fruits from each plant were selected for fruit quality studies based on uniformity of maturity (pink to red) and size (similar to fruit on other plants). In this way, possible confounding effects of fruit size variation among and within trusses (Fisher, 1977) were minimized. All other fruits were pierced and dried at $70 \mathrm{C}$ for 6 days.

Fruits were weighed and allowed to ripen to table red maturity for 3 days at $21 \mathrm{C}$ before measuring soluble solids concentration (SSC) and titratable-acidity. Their dry weights were estimated from percent dry matter of other fruit on the same plant and added to that of other fruits to obtain the total fruit dry weight per plant. SSC was determined in duplicate by the refractometer method (AOAC, 1975), using supernatants from shaken homogenates of 2 one-third sections from each fruit. Titratable acidity was determined in a homogenate from another one-third section, using a titrator and expressing the acidity as equivalent to percent citric acid (Dalal et al., 1965).

Data from the two harvests (i.e., 2 or 3 days after exposure and first red fruit) were analyzed separately. Growth and fruit weight data were transformed to natural logarithms before analysis, as the biomass of flowering stage plants was greater than 1.5 times (Snedecor and Cochran, 1980) that of the vegetative stage plants harvested 2 or 3 days after the end of $\mathrm{O}_{3}$ exposure. The fruit quality data were analyzed as percent SSC and percent citric acid without transformation. Combined analysis of variance and regression analysis were used to compare the nature of the relationship to $\mathrm{O}_{3}$ concentration between vegetative and flowering stage plants at each harvest period. The $\mathrm{CF}$ air was assumed to be $0.00 \mu \mathrm{O}_{3} /$ liter for the regression analysis.

Foliar injury symptoms ranged from general chlorosis of the fully mature leaves to chlorotic stippling on the adaxial leaf surfaces at $0.06,0.09$, and $0.12 \mu \mathrm{O}_{3}$ /liter, to monofacial and bifacial interveinal tan-colored necrosis at 0.18 and $0.24 \mu \mathrm{l} \mathrm{O}_{3}$ /liter. Foliar injury increased with increasing $\mathrm{O}_{3}$ concentration in a quadratic relationship in all cases (Fig. 1). There was greater injury on leaves exposed at the flowering than at the vegetative stage, whether rated 2 or 3 days after exposure (Fig. 1A) or at red fruit harvest (Fig. 1B). Since, 'New Yorker' is a semi-determinate cultivar, most of the foliage was fully expanded at flowering and greater injury might be expected at this stage. 

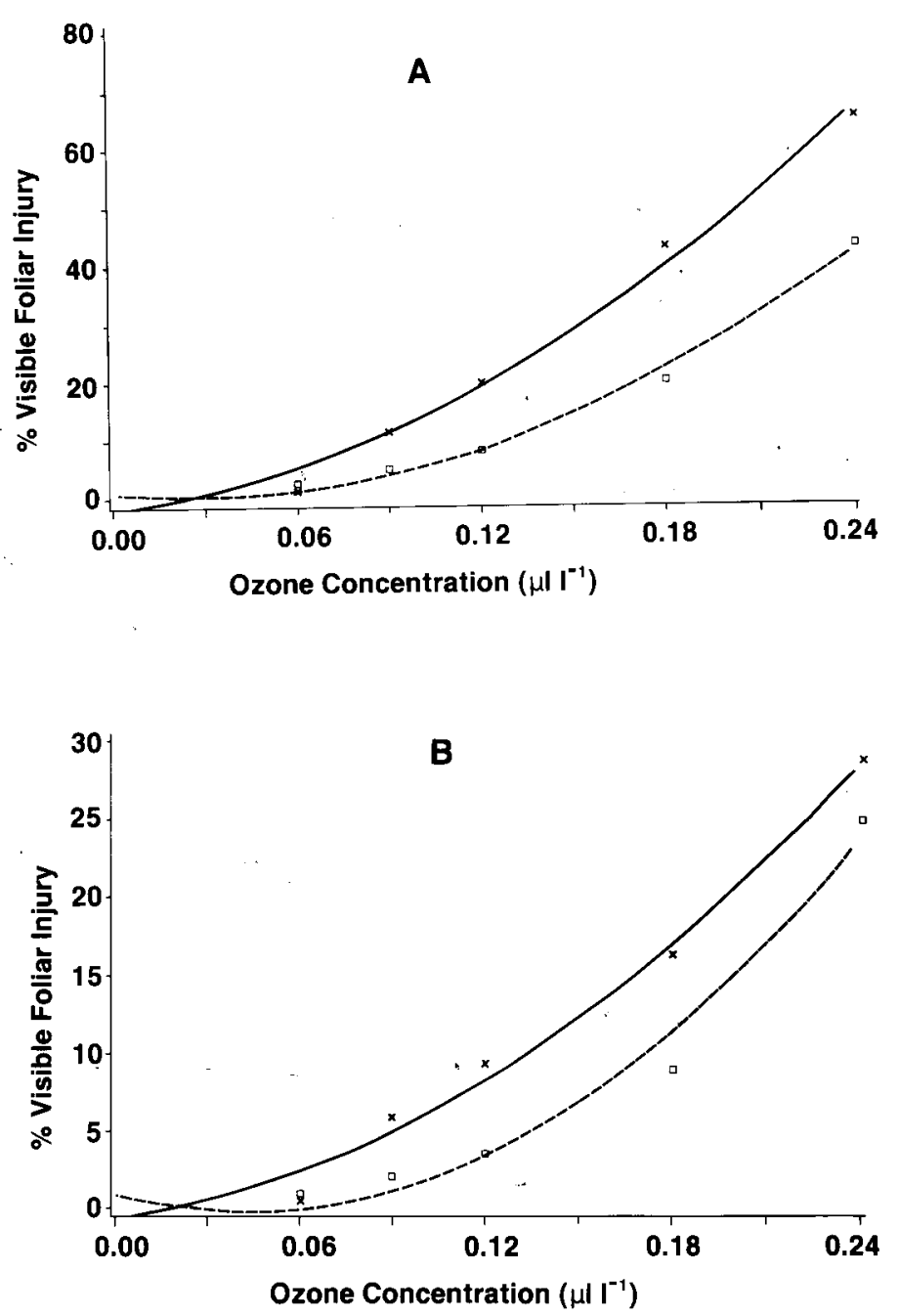

Fig. 1. Visible foliar injury of 'New Yorker' tomato to $\mathrm{O}_{3}$ treatments at vegetative and flowering stages. Plants were rated 2 or 3 days after exposure (A) or at first red fruit (B). Plants in (A) were rated at the two growth stages, whereas plants in $(\mathbf{B})$ were rated at the same growth stage. Regression equations: (A) $\mathrm{Y}_{\mathrm{V}}=0.87-49.6(\mathrm{X})+9.25(\mathrm{X})^{2}, \mathrm{Y}_{\mathrm{F}}=1.89+63.0(\mathrm{X})+930.0(\mathrm{X})^{2}$, common $R^{2}=0.89$; (B) Y. $=0.86-53.3(\mathrm{X})+619.2(\mathrm{X})^{2}, \mathrm{Y}_{\mathrm{F}}=-0.47+23.2(\mathrm{X})+408.5(\mathrm{X})^{2}$, common $R^{2}=0.91$; where $\mathrm{Y}_{v}=$ percent foliar injury response with $\mathrm{O}_{3}$ treatment at the vegetative stage, $\mathrm{X}=\mathrm{O}_{3}$ concentration in $\mu \mathrm{l} \cdot$ liter $^{-1}, \mathrm{Y}_{\mathrm{F}}=$ percent foliar injury response with $\mathrm{O}_{3}$ treatment at the flowering stage. $\square=$ Vegetative stage, $X=$ flowering stage.

This expectation is in agreement with a report that tomato plants had oxidant-injury indices for successive leaves from base to apex of $\mathrm{O}, 1.3,2.9,6.5,9.4,5.2,1.6$, and $\mathrm{O}$ (Middleton, 1961).

Both vegetative and flowering stage plants had a significant $(P \leq 0.05)$ linear decline in leaf area in response to increasing $\mathrm{O}_{3}$ concentration when harvested 2 or 3 days after exposure (data not shown). At the red fruit harvest, $\mathrm{O}_{3}$ treatment had little or no effect on leaf area. No evidence of defoliation was seen in either the vegetative or the flowering stage plants harvested 2 or 3 days after exposure or at first red fruit. Thus, the leaf area reductions were more likely due to reduced leaf expansion and/or leaf initiation (Endress and Grunwald, 1985). The $\mathrm{O}_{3}$ concentration-plant response relationship for leaf and stem dry weights was not significant $(P>$ 0.05 ) when plants were harvested either at 2 or 3 days after exposure or at first red fruit (data not shown). This finding is in agree- ment with an earlier report (Reinert and Henderson, 1980) that interaction of age, $\mathrm{O}_{3}$ dose, and cultivar was not significant for biomass variables of six tomato cultivars.

There was no significant relationship between number of fruits or fruit dry weight and $\mathrm{O}_{3}$ treatment. However, the interaction between $\mathrm{O}_{3}$ and growth stage at exposure for fruit fresh weight was highly significant $(P$ $\leq$ 0.01) (Fig. 2A). Plants exposed to $\mathrm{O}_{3}$ at flowering had a significant linear decrease $(P \leq 0.01)$ in fruit fresh weight with increasing $\mathrm{O}_{3}$, while the response for the vegetative stage plants was not significant. Oshima et al. (1975) found no significant difference in number of fruits between tomato plants receiving 0.00 or $0.20 \mu \mathrm{O}_{3} /$ liter for a total of $97 \mathrm{hr}$ during the growth period. However, $0.35 \mu \mathrm{O}_{3}$ /liter for the same duration led to a reduction in the number of fruits per plant. Their findings and ours suggest that there may be a tolerance level that must be exceeded before the number of tomato fruit is reduced. Reduction in tomato fruit fresh weight caused by $\mathrm{O}_{3}$ is well-documented (MacLean and Schneider, 1976; Oshima et al., 1975; Oshima et al., 1977b), but information is limited on tomato response to $\mathrm{O}_{3}$ in terms of fresh fruit yield after exposure to $\mathrm{O}_{3}$ at different developmental stages. Plants exposed to $\mathrm{O}_{3}$ up to 84 days after transplanting showed no yield effect, but at ages greater than this a cumulative yield decline was obtained (MacLean and Schneider, 1976).

Effects of $\mathrm{O}_{3}$ on fresh fruit yield were detectable in our study only when plants were exposed at flowering. A major implication is that the use of acute $\mathrm{O}_{3}$ injury response to predict cultivar differences in yield response under field conditions, as suggested by Heck et al. (1988) for bean, needs to be applied cautiously. Our results for tomato indicate that this prediction may be useful for $\mathrm{O}_{3}$ exposure at the flowering stage but not at the vegetative stage.

There were no significant effects of $\mathrm{O}_{3}$ on fruit $\operatorname{SSC}(P>0.05)$. Pippen et al. (1975) found no effect of $\mathrm{O}_{3}$ on total solids up to $0.20 \mu \mathrm{l} \cdot$ liter $^{-1}$ and a decrease at $0.35 \mu \mathrm{l}$. liter $^{-1}$. Fruit titratable acidity (Fig. 2B), however, had a strong interaction between $\mathrm{O}_{3}$ concentration and growth stage at exposure $(P \leq 0.01)$; titratable acidity of fruits was affected by $\mathrm{O}_{3}$ only for plants exposed at the flowering stage. The relationship was quadratic with weak curvature; acidity first declined and then leveled off in response to increasing $\mathrm{O}_{3}$ concentration. Since $\mathrm{O}_{3}$ was not applied directly to the fruits, the carryover effects could be through altered partitioning of substances arriving in the fruits from leaves or through compositional changes, other than direct oxidation, occurring in the fruits. This reasoning is partly supported by the finding that some acids, such as ascorbic, can be lowered in plant leaves by $\mathrm{O}_{3}$ exposure (Guri, 1983). In plants exposed at the vegetative stage, the nonsignificant response may be partly explained by compensatory regrowth and reestablishment of the normal composition of partitioned photosynthate to fruits (Cooley and Manning, 1987).

It should be noted that the interpretation of fruit SSC and titratable acidity data must be in the context of the sampling technique used. Fruits of similar size and maturity were selected for analysis even though the treatments may have had an effect on fruit size. Further experiments should attempt to separate the effects of $\mathrm{O}_{3}$ treatments and of fruit size and maturity on fruit quality characteristics and define the interaction among those variables. The present experiment also did not address the complex issues of dry-matter partitioning and organ growth and the apparent anomalies that appear in the data and their analysis. Fresh fruit weights were reduced by $\mathrm{O}_{3}$ treatment at the flowering stage but dry weights were not. This implies higher percent dry matter in fruits of $\mathrm{O}_{3}$-treated vs. nontreated plants and requires an explanation of why fruits of $\mathrm{O}_{3}$-treated plants do not expand normally and achieve the same water content as those of nontreated plants. Tomato fruit growth is the subject of current 
A

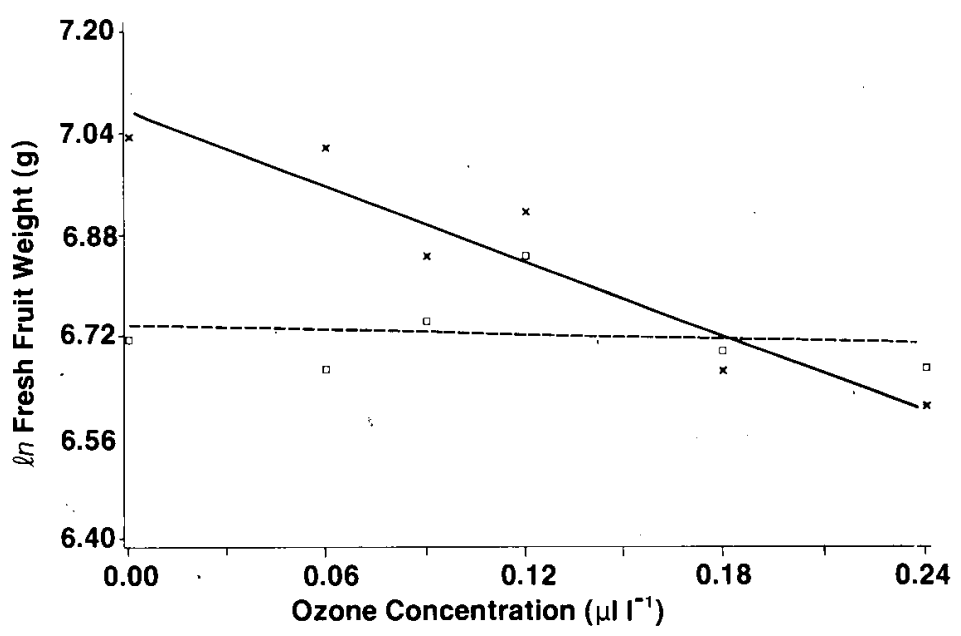

B

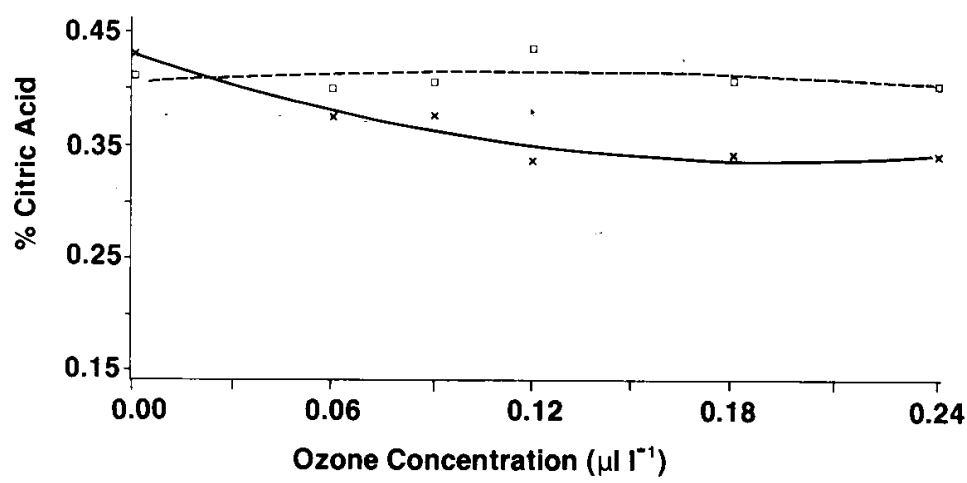

Fig. 2. Comparisons of fruit fresh weight (A) and titratable acidity (B) in 'New Yorker' tomato exposed to $\mathrm{O}_{3}$ at vegetative and flowering stages. Plants in both $(\mathbf{A})$ and $(\mathbf{B})$ were harvested at the same (first red fruit) growth stage. Regression equations: (A) $\mathrm{Y},=6.74-0.13(X), R^{2}=0.92$; $\mathrm{Y}_{\mathrm{F}}=7.07-1.94(\mathrm{X}), R^{2}=0.82 ;(\mathrm{B}) \mathrm{Y}_{\mathrm{V}}=0.406+0.16(\mathrm{X})-0.69(\mathrm{X})^{2}, R^{2}=0.30 ; \mathrm{Y},=$ $0.430-0.99(\mathrm{X})+2.60(\mathrm{X})^{2}, R^{2}=0.91$; where $\mathrm{Y}_{\mathrm{v}}=$ in fruit fresh weight (per plant) or titratable acidity (percent citric acid) with $\mathrm{O}_{3}$-treatment at the vegetative stage, $\mathrm{X}=\mathrm{O}_{3}$ concentration in $\mu l \cdot l i t e r^{-1} Y_{F}=$ In fruit fresh weight $(\mathrm{g} / \mathrm{plant})$ or titratable acidity (percent citric acid) with $\mathrm{O}_{3}$ treatment at the flowering stage. $\square=$ Vegetative stage, $X=$ flowering stage.

research elsewhere (Ho et al., 1987).

The $\mathrm{O}_{3}$ levels used in this study are fairly characteristic of polluted agricultural areas in Canada and the United States, so tomato yields and quality could be at real risk in North America. Reduced fruit fresh weight and titratable acidity in response to $\mathrm{O}_{3}$ depended on the growth stage at exposure. This relationship indicates that ontogenic differences in tomato plants and the available growth period for compensatory regrowth may be important factors to consider in tomato response to $\mathrm{O}_{3}$ stress and for developing pre-
Cooley, D.R. and W.J. Manning. 1987. The impact of ozone on assimilate partitioning in plants: A review. Env. Pollut. 47:95-113.

Dalal, K.B., K.K. Salunkhe, A.A. Boe, and L.E. Olson. 1965. Certain physiological and biochemical changes in the developing tomato fruit (Lycopersicon esculentum Mill.). J. Food Sci. 30:504-508.

Endress, A.G. and C. Grunwald. 1985. Impact of ozone on soybean growth and biomass partitioning. Agr. Ecosystems Env. 13:9-23.

Fisher, K.J. 1977. Competition effects between fruit trusses of the tomato plant. Scientia Hort. 7:37-42.

Guri, A. 1983. Variation in glutathione and ascorbic acid content among selected cultivars of Phaseolus vulgaris prior to and" after exposure to ozone. Can. J. Plant Sci. 63:733-737.

Heagle, A.S., D.E. Body, and W.W. Heck. 1973. An open-top field chamber to assess the impact of air pollution on plants. J. Env. Qual. 2:365368.

Heck, W.W., J. A. Dunning, R.A. Reinert, S.A. Prior, M. Rangappa, and P.S. Benepal. 1988. Differential responses of four bean cultivars to chronic doses of ozone. J. Amer. Soc. Hort. Sci. 113:46-51.

Ho, L.C., R.I. Grange, and A.J. Picken. 1987. An analysis of the accumulation of water and dry matter in tomato fruit. Plant Cell Environ. 10:157-162.

Hoagland, D.R. and D. I. Arnon. 1950. The water culture method for growing plants without soil Calif. Agr. Expt. Sta. Circ. 347:1-32.

Horsfall, J.G. and R.W. Barratt. 1945. An improved grading system for measuring plant diseases. Phytopathology 35:665. (Abstr.)

MacLean,. D.C. and R.E. Schneider. 1976. Photochemical oxidants in Yonkers, New York: Effects on yield of bean and tomato. J. Env. Qual. 5:75-78.

Middleton, J.T. 1961. Photochemical air pollution damage to plants. Annu. Rev. Plant Physiol. $12: 431-448$

Ormrod, D.P. 1986. Gaseous air pollution and horticultural crop production. Hort. Rev. 8:142.

Oshima, R.J., O.C. Taylor, P.K. Braegelmann, and D.W. Baldwin. 1975. Effect of ozone on the yield and plant biomass of a commercial variety of tomato. J. Env. Qual. 4:463-464.

Oshima, R.J., P.K. Braegelmann, D.W. Baldwin, V. Van Way, and O.C. Taylor. 1977a Responses of five cultivars of fresh market tomato to ozone: a contrast of cultivar screening with foliar injury and yield. J. Amer. Soc. Hort. Sci. 102:286-289.

Oshima, R.J., R.K. Braegelmann, D.W. Baldwin, V. Van Way, and O. C. Taylor. 1977h. Reduction of tomato fruit size and yield by ozone. J. Amer. Soc. Hort. Sci. 102:289-293.

Pippen, E.L., A.L. Potter, V.G. Randall, K.C. Ng, F.W. Reuter, A.I. Morgan, and R.J. Oshima. 1975. Effect of ozone fumigation on crop composition. J. Food Sci. 40:672-676.

Reinert, R.A. and W. R. Henderson. 1980. Foliar injury and growth of tomato cultivars as influenced by ozone dose and plant age. J. Amer. Soc. Hort. Sci. 105:322-324.

Snedecor, G.W. and W.G. Cochran. 1980. Statistical methods. 7th ed. The Iowa State Univ. Press, Ames. 